\title{
Indicators of mineral-energy metabolism in cows of different physiological state when feeding tanamine Zn
}

\author{
Alexander Omelchuk ${ }^{1}$, Irina Kramareva ${ }^{1}$, Vladimir Semenyutin ${ }^{1}$, Victor Eremenko $^{2}$ \\ ${ }^{1}$ Belgorod State Agrarian University named after V.Ya. Gorin, Belgorod Region, Belgorod District, Maysky Village, 1 \\ Vavilova Street, Russia \\ ${ }^{2}$ Kursk State Agricultural Academy named after I.I. Ivanov, Kursk region, Kursk city, 70 Karl Marx Street, Russia
}

\begin{abstract}
The paper presents the experimental results to study the effect of Tanamine $\mathrm{Zn}$ complex preparation on the mineral-energy metabolism of dry and newly calved highly productive (with an amount of more than 8 thousand $\mathrm{kg}$ ) cows. During the dry period (60 days), the preparation was administered at $20.0 \mathrm{~g} / \mathrm{head} / \mathrm{day}$. The metabolites under study were monitored at the beginning, middle and end of the dry period (60, 30, 15-10 days before calving), as well as on the 15 and 30 days after calving. 15 days before calving the use of the additive led to an increase in calcium concentrations by $27.1 \%(\mathrm{p}<0.05)$, magnesium - by $37.7 \%(p<0.05)$, chlorine - by $12.7 \%(p<0.001)$ and cholesterol - by $13.1 \%(p>0.05)$. The effect of tanamine $\mathrm{Zn}$ on newly calved cows 15 and 30 days after calving led to multi-directional changes in the studied indicators: an increase in the activity of alkaline phosphotase - by $48.9 \%$ and $67.9 \%(\mathrm{p}<0.05)$, an increase in the concentration of magnesium - by $104.6 \%$ and $50.0 \%(\mathrm{p}<0.001)$, potassium - by $12.0 \%$ and $13.1 \%(p<0.05)$ with a decrease in cholesterol - by $45.4 \%(\mathrm{p}<0.01)$ and $55.3 \%(\mathrm{p}<0.001)$ respectively). Besides, on the $30^{\text {th }}$ day after calving, feeding tanamine $\mathrm{Zn}$ led to a decrease in glucose by $38.3 \%$ $(\mathrm{p}<0.001)$.
\end{abstract}

\section{Introduction}

Modern intensive technologies for keeping dairy cattle imply the use of biologically complete feeding, without which the rational use of the genetic potential of animals is impossible [1,2]. With increasing productivity of the latter, it becomes necessary to find new highly effective additives including biologically active substances [3].

They take on the greatest importance during critical periods of life. For highly productive cows, the most "heavy", from the point of view of metabolic stress, are dry and newly calved periods.

During dryness, along with the intensive growth of the fetus (especially during the last two decades of pregnancy), the reserves of energy and plastic elements consumed by the body during the previous lactation are restored.

During the days in milk, the body wastes significant amounts of previously restored reserves for two simultaneous processes - lactation and involution of uterus (restoration of the histostructure of the uterus, which in highly productive cows lasts up to 80 days after calving). The tension of current processes is aggravated by the lack of readiness of the digestive system to process the corresponding amount of feed and assimilate the necessary components from it. Therefore, the nutritional status of animals, in addition to the main nutrients (proteins, fats and carbohydrates) supplied with food in the given periods is ensured by the additional introduction of biologically active substances (amino acids, vitamins, microelements, etc.).

Traditionally, the animal body was provided with microelements due to mineral salts, but up to $40 \%$ of them were not absorbed [4]. Currently, in order to supply the body with mineral substances (copper, cobalt, manganese, zinc, etc.) in a more accessible form, complex compounds with biological ligands - organic acids are used. The effectiveness of chelate complexes with amino acids in the composition of biologically active additives was reported by D.V. Pchelnikov et al. [5], A. Frolov et al. [6], M.I. Selionova and E.M. Golovkina [7], M.G. Chabaev et al. [8], S.L. Vieira [9] and others.

Chelates are absorbed not as metal ions, but as amino acids. Due to greater biological activity and better assimilation, they contribute to a positive balance of nitrogen, calcium and phosphorus in lactating cows [10], improve reproductive function, increase nutrient digestibility, productivity and body resistance [11, 12].

Considering that cows with a productivity per day of $20-25 \mathrm{~kg}$ of milk and above lose significant amounts of mineral substances, it is necessary to control their level not only in the diet, but also in the blood of animals, because the metabolic disorder reduces resistance, reproductive function and increases the frequency of various pathologies, and there is a need to control microelements in the blood $[13,14,15,16]$.

Some feed additives include tannins - polyphenolic water-soluble compounds. The latter are widely used in

\footnotetext{
*Corresponding author: vic.eriomenko@yandex.ru
} 
pig breeding using their property to suppress the growth of pathogenic microflora, to influence the anti-oxidative activity, as well as the binding and tanning effect on feed proteins.

For ruminants, the Farmatan TM feed additive is known, the main active substance of which is tannins. They reduce protein breakdown, ammonia and methane formation in proventriculi, as well as the risk of acidosis and ketosis [17].

To some extent, Tanamine $\mathrm{Zn}$ is the analogue of Farmatan TM in terms of the ingredients included in the feed additive. Its feeding in the dry period showed a positive effect on the reproductive function of cows, which was expressed in a decrease in the number of cows with postpartum complications, a reduction in the indifferse and service periods, a decrease in the insemination index, as well as the possibility of obtaining calves with higher body weight, both at birth and at monthly age [18].

In view of all the above, the purpose of the study was to analyze the state of mineral-energy metabolism in the body of highly productive cows using the Tanamine $\mathrm{Zn}$ feed additive, which includes zinc glycinate, chestnut extract, amino acids lysine and methionine.

\section{Materials and methods}

The experimental part of the work was carried out on black-and-white cows (Bessonovsky type) in the conditions of the collective farm-breeding plant named after V.Ya. Gorin, Belgorod region. The type of feeding is silo-concentrate. Access to food and water is free. The average milk yield of the herd over the past 5 years was $8400 \mathrm{~kg}$ of milk.

The groups were formed during the launch period from mature analogue animals by origin, age, body weight, number of lactations and physiological state.

40 heads were selected for the experience, of which 2 groups were formed (I - control and II - experimental), 20 heads each. Observation was carried out during dry and fresh periods.

Animals of both groups received a basic diet (BD), the composition of which was changed depending on the physiological state of cows (Table 1).

The ration of the dry period 1 had a weight of 27.39 $\mathrm{kg}$ (dry matter - $12.18 \mathrm{~kg}$ ), dry 2 (20 days before calving) $-26.80 \mathrm{~kg}$ (dry matter $-12.03 \mathrm{~kg}$ ). The total weight of the diet of newly calved cows (from 0 to 20 days) was $37.43 \mathrm{~kg}$ (dry matter - $19.15 \mathrm{~kg}$ ), and cows from 20 to 150 days after calving $-46.03 \mathrm{~kg}$ (dry matter $-23.94 \mathrm{~kg}$ ).

In order to prevent the development of acidosis in newly calved cows, soda was introduced into the diet.
Table 1. Composition of diets for feeding cows of different physiological state, $\mathrm{kg}$

\begin{tabular}{|c|c|c|c|c|}
\hline \multirow{3}{*}{ Ingredients } & \multicolumn{4}{|c|}{ Physiological state } \\
\hline & \multicolumn{2}{|c|}{ Dry cows } & \multicolumn{2}{|c|}{ Lactating cows } \\
\hline & $\begin{array}{c}\text { Dry } \\
\text { period } 1\end{array}$ & $\begin{array}{c}\text { Dry } \\
\text { period } \\
2\end{array}$ & $\begin{array}{l}0-20 \\
\text { days }\end{array}$ & $\begin{array}{c}20-150 \\
\text { days }\end{array}$ \\
\hline $\begin{array}{l}\text { Barley } \\
\text { straw }\end{array}$ & 3.5 & 2.3 & 2.3 & - \\
\hline Alfalfa hay & 2.0 & 1.2 & 1.9 & 2.0 \\
\hline Corn silage & 12.5 & 14.0 & 17.0 & 22.0 \\
\hline $\begin{array}{l}\text { Green mass } \\
\text { of alfalfa }\end{array}$ & 8.0 & 6.5 & 7.5 & 8.0 \\
\hline $\begin{array}{l}\text { Combined } \\
\text { feed: }\end{array}$ & & & & \\
\hline for dry cows & 1.35 & 1.35 & 8.0 & 8.0 \\
\hline $\begin{array}{l}\text { for } \\
\text { newly } \\
\text { calved }\end{array}$ & - & 1.0 & 8.2 & 10.8 \\
\hline $\begin{array}{ll}\text { Rape } & \text { cake } \\
37 \% & \end{array}$ & - & 0.4 & 1.5 & 2.2 \\
\hline Glycerin & - & - & 0.2 & - \\
\hline Feeding fat & - & - & 0.2 & - \\
\hline Salt & 0.040 & - & 0.035 & 0.075 \\
\hline Soda & - & - & 0.09 & 0.15 \\
\hline
\end{tabular}

The cows of group I were given a BD and group II were fed Tanamine $\mathrm{Zn}$ at a dose of $20.0 \mathrm{~g} / \mathrm{head} /$ day daily for a dry period in addition to the BD (the dose was previously determined as optimal).

Table 2. Experimental design

\begin{tabular}{|c|c|c|}
\hline Group & $\begin{array}{c}\text { Number of } \\
\text { animals, heads }\end{array}$ & Administration dose \\
\hline I-control & 20 & BD \\
\hline II & 20 & $\begin{array}{c}\text { BD + Tanamine Zn 20.0 } \\
\text { g/head/day }\end{array}$ \\
\hline
\end{tabular}

The blood for analysis was taken from cows at the beginning (60 days), middle (30 days) and end of the dry period (15-10 days), as well as after calving (15 and 30 days). The blood was taken from the tail vein 3.0-3.5 hours after morning feeding from 5 animals from each group (into vacuum disposable tubes using Vacuette vacuum system).

Biological material was analyzed in Belgorod Interregional Veterinary Laboratory.

The obtained material was processed statistically using Microsoft Excel 2016. The validity of obtained results was assessed by the Student's t-test. The results were considered reliable starting from $\mathrm{p} \leq 0.05$.

\section{Research results}

One of the studied indicators characterizing mineral exchange is alkaline phosphatase (Table 3). 
Table 3. Indicators of mineral-energy metabolism in cows during dry period

\begin{tabular}{|l|c|c|c|c|c|c|}
\hline \multirow{2}{*}{ Indicators } & \multicolumn{2}{|c|}{ Over 60 days } & \multicolumn{2}{c|}{ Over 30 days } & \multicolumn{2}{c|}{ Over 15 days } \\
\cline { 2 - 7 } & I-control & II & I-control & II & I-control & II \\
\hline Alkaline phosphatase, E/L & $61.0 \pm 5.1$ & $59.2 \pm 3.7$ & $52.2 \pm 4.8$ & $60.1 \pm 4.3$ & $46.0 \pm 3.5$ & $48.2 \pm 2.8$ \\
\hline Phosphorus, mmol/L & $1.87 \pm 0.07$ & $2.28 \pm 0.16^{*}$ & $1.82 \pm 0.04$ & $1.84 \pm 0.10$ & $1.84 \pm 0.16$ & $1.83 \pm 0.13$ \\
\hline Calcium, mmol/L & $2.14 \pm 0.01$ & $2.40 \pm 0.11^{*}$ & $2.26 \pm 0.02$ & $2.19 \pm 0.06$ & $1.88 \pm 0.19$ & $2.39 \pm 0.04^{*}$ \\
\hline Magnesium, mmol/L & $0.83 \pm 0.02$ & $1.05 \pm 0.01^{* * *}$ & $0.81 \pm 0.01$ & $0.91 \pm 0.10$ & $0.74 \pm 0.06$ & $1.02 \pm 0.05^{*}$ \\
\hline Potassium, mmol/L & $5.11 \pm 0.17$ & $4.73 \pm 0.24$ & $5.00 \pm 0.13$ & $4.61 \pm 0.20$ & $4.85 \pm 0.07$ & $4.78 \pm 0.32$ \\
\hline Chlorine, $\mathrm{mmol} / \mathrm{L}$ & $97.31 \pm 0.83$ & $85.07 \pm 9.54$ & $95.88 \pm 1.37$ & $91.43 \pm 2.05$ & $91.91 \pm 1.75$ & $103.60 \pm 0.32^{* * *}$ \\
\hline Glucose, $\mathrm{mmol} / \mathrm{L}$ & $2.08 \pm 0.44$ & $1.61 \pm 0.30$ & $2.23 \pm 0.49$ & $1.22 \pm 0.09$ & $2.38 \pm 0.30$ & $2.26 \pm 0.38$ \\
\hline Cholesterol, mmol/L & $2.50 \pm 0.18$ & $3.88 \pm 0.25^{*}$ & $2.74 \pm 0.23$ & $2.54 \pm 0.38$ & $2.45 \pm 0.49$ & $2.79 \pm 0.25$ \\
\hline
\end{tabular}

Note: hereinafter $*$ - difference is valid with respect to the control group; $* \mathrm{p}<0.05 ; * * \mathrm{p}<0.01 ; * * * \mathrm{p}<0.001$

In the blood of the animals of the control group the activity of alkaline phosphatase successively decreased at the level of trend from the beginning of the dry period to its middle by $14.4 \%$ and to the end relative to the middle - by $11.9 \%$ ( $p>0.05)$. In general, from the beginning of the dry period to its end, the activity of this enzyme in the control group decreased by $24.6 \%$ $(\mathrm{p}<0.05)$.

Unlike the animals of the control group, in cows treated with Tanamine $\mathrm{Zn}$, the activity of alkaline phosphatase from the beginning of the dry period to its middle remained unchanged. However, by its end relative to the middle, the decrease was $19.8 \%(\mathrm{p}<0.05)$ and just as in the control relative to the beginning of the period it decreased by $18.6 \%(\mathrm{p}<0.05)$.

Recognizing the importance of many macro- and microelements in the metabolism and productivity of animals, special attention should be paid to magnesium as one of the most important macroelement. Without dwelling in detail on its role in the body, it should be noted that it is present in all tissues of the body, including bone (about 60\%). Magnesium, being a cofactor of many enzymes, is involved in more than 300 biochemical reactions [19].

We showed the absence of changes in magnesium concentration by the middle of the dry period relative to its beginning and the tendency of its further decrease by the end of the period in the control group and some increase in the blood of animals of the experimental group. When compared with the control group, it was shown that the magnesium concentration in the test group by the middle of the dry period significantly decreased by $14.3 \%(\mathrm{p}<0.001)$, and then increased by $12.1 \%(\mathrm{p}<0.05)$.

Other equally important macroelements are calcium and phosphorus. To a certain extent, their concentration and ratio in the blood also characterize the state of mineral metabolism.

The level of phosphorus in the blood of the cows of group I remained unchanged throughout the final stage of pregnancy, while calcium showed a downward trend of $16.8 \%$, probably due to its increased response in the fetal bone tissue. It should be noted that in the cows of group II, neither calcium nor phosphorus in the blood underwent significant changes over the entire dry period.
The concentrations of potassium and chlorides during the dry period almost did not change in the control group, while in animals receiving the test additive, the concentration of chlorides significantly increased within the group by $13.3 \%$, and in relation to the control - by $12.7 \%$ during the same period.

The glucose content is one of the most important energy metabolites of the blood - in both groups at the beginning and mid-dry period it was below normal. At the same time, it should be noted that in the control group it was higher than in experimental by 22.6 and $45.3 \%$, respectively.

By the end of the dry period, the blood glucose level of control animals increased (relative to the middle) by $6.7 \%$, and in the experimental group - by $85.4 \%$. At the same time, the growth of this indicator relative to the beginning of the dry period was $14.4 \%$ in group I and $40.4 \%$ in group II and reached the lower limit of reference values in both groups (norm 2.3-4.1 mmol/l).

L.K. Buslovskaya and A.Yu. Kovtunenko [20] believe that a decrease in the concentration of this energy metabolite indicates a depletion of glycogen reserves in the liver. At the same time, according to E.V. Gromyko [21], it is possible to reduce the glucose concentration in highly productive cows to $1.67-2.50$ $\mathrm{mmol} / \mathrm{l}$. He explains this fact by the use of this available metabolite in synthesis and by the limited flow into the blood from the gastrointestinal tract.

Cholesterol is an integral indicator reflecting metabolism and energy, and generally characterizes the state of lipid metabolism [22]. The concentration of this metabolite in group I over the dry period remained practically at baseline, as shown in Table 3 .

In group II, which consumed Tanamine $\mathrm{Zn}$, the situation is slightly different, namely: a reliable decrease relative to the initial to the middle of the dry period by $35.5 \%(\mathrm{p}<0.05)$, and then unreliable growth towards the end of the dry period (relative to the middle) by $9.8 \%$ $(p>0.05)$. In general, the cholesterol level in the blood of the cows of the experimental group by the end of the dry period was inaccurately lower than in the control group by $13.8 \% \quad(p>0.05)$, which, apparently, could have a favorable effect on the reproductive function.

In the first 100 days of lactation, the alkaline phosphatase enzyme, along with alanine aminotransferase, aspartate aminotransferase and 
amylase, occupies key positions in the regulation of the main metabolic reactions [23]. Table 4 shows that it is possible to trace the increased activity of phosphatase in the cows of group II, as well as the growth in the post- calving period in relation to the dry. Unlike animals that consumed Tanamine $\mathrm{Zn}$ in the dry period, we did not note an increase in the activity of alkaline phosphatase in the control group after calving.

Table 4. Indicators of mineral-energy metabolism in cows after calving

\begin{tabular}{|l|c|c|c|c|}
\hline \multirow{2}{*}{\multicolumn{1}{|c|}{ Indicators }} & \multicolumn{2}{c|}{ Over 15 days } & \multicolumn{2}{c|}{ Over 30 days } \\
\cline { 2 - 5 } & I-control & II & I-control & II \\
\hline Alkaline phosphatase, E/L & $43.1 \pm 4.6$ & $64.2 \pm 6.3^{*}$ & $35.3 \pm 2.2$ & $59.3 \pm 7.7^{*}$ \\
\hline Phosphorus, mmol/L & $1.87 \pm 0.23$ & $1.91 \pm 0.12$ & $1.74 \pm 0.01$ & $1.62 \pm 0.17$ \\
\hline Calcium, mmol/L & $2.76 \pm 0.05$ & $2.83 \pm 0.06$ & $2.74 \pm 0.03$ & $2.35 \pm 0.19$ \\
\hline Magnesium, mmol/L & $0.65 \pm 0.04$ & $1.33 \pm 0.083^{* * *}$ & $0.80 \pm 0.05$ & $1.20 \pm 0.021^{* * *}$ \\
\hline Potassium, mmol/L & $5.02 \pm 0.03$ & $5.62 \pm 0.21^{*}$ & $4.81 \pm 0.16$ & $5.44 \pm 0.12^{*}$ \\
\hline Chlorine, mmol/L & $90.59 \pm 2.02$ & $87.38 \pm 10.27$ & $91.29 \pm 1.78$ & $90.77 \pm 5.36$ \\
\hline Glucose, $\mathrm{mmol} / \mathrm{L}$ & $3.90 \pm 0.25$ & $3.49 \pm 0.29$ & $4.07 \pm 0.16$ & $2.51 \pm 0.06^{* * *}$ \\
\hline Cholesterol, mmol/L & $4.49 \pm 0.39$ & $2.45 \pm 0.17 * *$ & $6.74 \pm 0.34$ & $3.01 \pm 0.51^{* * *}$ \\
\hline
\end{tabular}

In group II on the $15^{\text {th }}$ day after calving an increase in

The trend noted earlier to reduce the level of magnesium in the control group 15 days before calving (Table 3) was preserved in the first 15 days after it (Table 4). At the same time, the magnesium level in the control group decreased by $12.2 \%$, while the experimental group showed a significant increase in magnesium concentration by $30.4 \% \quad(\mathrm{p}<0.05)$. The difference with the control group was $104.6 \%$ $(\mathrm{p}<0.001)$.

On the $30^{\text {th }}$ day, the concentration of this element in the control group increased by $23.1 \%$, and in animals within the II group - decreased by $9.8 \% \quad(p>0.05)$, although in relation to the control group it remained higher by $50.0 \%$, $(\mathrm{p}<0.001)$.

On the $15^{\text {th }}$ day after calving, the calcium level in the blood of cows of both groups significantly increased $(p<0.01)$ : in the control - by $45.7 \%$ and in the experimental - by $18.4 \%$. It is characteristic that on the $30^{\text {th }}$ day after calving in the control group the calcium content remained at the same level, and in the experimental group, a $17 \%$ decrease was noted.

Phosphorus is an element that involves all energy processes in the body. The concentration of this element in the animals of both groups 15 days after calving practically did not change, and after 30 days in the control group decreased by $7 \%$, and in the experimental - by $15.2 \%$ ( $p>0.05)$. Given earlier data on higher (by $13.5 \%$ ) productivity of cows in the experimental group and the fact that in the first stage of lactation from the depot (skeleton) up to $40 \%$ mineral substances are used, mainly calcium and phosphorus [24], the shown decrease in their concentrations is quite natural.

One of the most important metabolites of blood glucose - is spent in significant quantities on milk synthesis. It plays an essential role as a substrate for the synthesis of milk fat and the provision of energy to the body. The blood glucose concentration of cows of the control group on the $15^{\text {th }}$ day after calving increased relative to the previous observation period (15 days before calving) by $63.9 \% \quad(\mathrm{p}<0.01)$ and practically remained at the same level by the $30^{\text {th }}$ day after calving. the concentration of this metabolite was also recorded by $54.4 \%(\mathrm{p}<0.05)$ relative to the previous study period. However, unlike the control group, by the month after calving, the blood glucose concentration decreased by $28.1 \%(\mathrm{p}<0.01)$ and became significantly lower than in the control group by $38.4 \%(\mathrm{p}<0.001)$. In accordance with the opinion of L.K. Buslovskaya and A.Yu. Kovtunenko [20], it is possible to assume the depletion of glycogen reserves in the body of cows of the experimental group.

A component of cell membranes - cholesterol plays an important role in the postpartum rehabilitation of animals. During this period, the desquamating uterine epithelium is replaced with a new one [25] and the synthesis of the secretory epithelium of the breast, so there is a sharp increase in its concentration in the blood [26].

The concentration of cholesterol in the blood of cows of the control group at both control points noted above (15 and 30 days after calving) significantly increased compared to the previous period by $83.3(\mathrm{p}<0.05)$ and $50.1 \%(\mathrm{p}<0.01)$, respectively.

In the experimental group on the $15^{\text {th }}$ day after calving the cholesterol level incorrectly decreased within the group by $12.2 \%$, and on the $30^{\text {th }}$ day it increased by $22.9 \%$ compared to the corresponding previous observation points. In general, the cholesterol level in the control group in both time intervals noted above was significantly greater than in the experimental group.

\section{Conclusion}

Thus, the use of Tanamine $\mathrm{Zn}$ in the dry period led to an increase in calcium concentrations by $27.1 \%(\mathrm{p}<0.05)$, magnesium - by $37.7 \%$ ( $\mathrm{p}<0.05)$, chlorine - by $12.7 \%$ $(\mathrm{p}<0.001)$ and cholesterol - by $13.1 \%(\mathrm{p}>0.05)$. In the fresh period (15 and 30 days after calving) under the influence of the additive differently directed changes in the content of the analyzed metabolites were noted: an increase in the activity of alkaline phosphotase - by 48.9 and $67.9 \%(\mathrm{p}<0.05)$, magnesium concentration - by 104.6 and $50.0 \%(\mathrm{p}<0.001)$, potassium - by 12.0 and $13.1 \%(\mathrm{p}<0.05)$ with a decrease in cholesterol - by 45.4 $(\mathrm{p}<0.01)$ and $55.3 \%(\mathrm{p}<0.001)$ respectively). Besides, on 
the $30^{\text {th }}$ day after calving under the influence of Tanamine $\mathrm{Zn}$ a decrease in glucose by $38.3 \%$ was shown $(\mathrm{p}<0.001)$.

\section{References}

1. V.I. Eremenko Functional reserves of the endocrine system in the prediction of dairy productivity (Kursk: Publishing House of Kursk State Agrarian Academy, 2010)

2. V.I. Eremenko, O.B. Sein Metabolic status, nonspecific resistance and their correction in cattle (Kursk: Business Printing Publishing House, 2011).

3. V.V. Semenyutin, I.A. Kramareva, I.V. Kramarev International Journal of Advanced Biotechnology and Research, 10 (1), 8-16 (2019)

4. B. Ebbinge Chief Livestock Engineer 5, 25-27, (2007).

5. D.V. Pchelnikov Veterinary pathology, 2, 47-48 (2005)

6. A. Frolov, O. Filippova, V. Li, Animal husbandry of Russia, 5, 41-42, (2010)

7. M.I. Selionova, E.M. Golovkina Agro-industrial portal of southern Russia. Retrieved from: http://agroyug.ru

8. M. Chabaev, R. Nekrasov, V. Nadeev Combined feed, 6, 77-79, (2013)

9. S. L. Vieira Brazilian Journal of Poultry Science. 2, 73-76, (2008)

10. N.A. Chepelev, I.S. Kharlamov Bulletin of Kursk State Agricultural Academy. 9, 1-3, 2013.

11. B.D. Kalnitsky, Mineral substances in the feeding of agricultural animals. (Moscow: Agropromizdat, 1985).

12. R. G. Bineev, H. S. Kazakov Chelates of microbiogenic metals in the soil-plant-animal system (Kazan study manual, 1987).

13. S. Kuznetsov, A. Kuznetsov, T. Kuznetsova Dairy and meat cattle breeding 5, 21-24, (2007)

14. T.S. Kuznetsova, S.G. Kuznetsov, A.S. Kuznetsov Zootechny. 8, 10-15, (2007).

15. N.V. Kuznetsova, L.V. Sycheva, Zootechny. 4, 46, (2009)

16. N. Mukhina, A. Smirnova, A. Smirnov, Feeding of farm animals and fodder production, 7, 41-42, (2007).

17. T.M. Farmatan Retrieved from: http://ibsagro.ru/index.php/produktsiya/skotovods tvo/18-molochnaya-produktivnost/40-farmatantm.

18. A.I. Omelchuk, V.V. Semenyutin, I.A. Kramareva, V.M. Artyukh International Bulletin of Veterinary Medicine 2 (2021)

19. A. Leninger, Fundamentals of biochemistry (Moscow: Mir, 1985)

20. L.K. Buslovskaya, A.Yu. Kovtunenko Scientific bulletin, Series of Natural Sciences. 11 (232), 35, 107-116, (2016).

21. E.V. Gromyko, Environmental Bulletin of the North Caucasus, 2, 80-94, (2005).
22. V.A. Mayorov, A.Yu. Kozlovskaya Bulletin of Velikolukskaya SAA, 2, 14-19, (2015)

23. A.G. Kudrin, Blood enzymes and prediction of dairy livestock productivity. (Michurin Publishing House. State Agrarian University, 2006)

24. O.A. Basonov Zootechny. 5, 7-8, (2005).

25. O.S. Epanchintseva, V.Ya .Nikitin, V.I. Pleshakova, Electronic scientific journal Modern problems of science and education. 5, (2013)

26. V. G. Priodchikov, O.G. Shlyakhova, D.P. Dubinina, T.A. Sen Scientific Journal of KubSAU, 79 (05), 1-20, (2012). 